\title{
Clinical Decision Support System with Renal Dose Adjustment Did Not Improve Subsequent Renal and Hepatic Function among Inpatients: The Japan Adverse Drug Event Study
}

Ryuhei Wada ${ }^{1}$ jiro Takeuchi ${ }^{1}$ Tsukasa Nakamura ${ }^{2}$ Tomohiro Sonoyama ${ }^{3}$ Shinji Kosaka ${ }^{4}$ Chisa Matsumoto $^{5}$ Mio Sakuma ${ }^{1}$ Yoshinori Ohta ${ }^{6}$ Takeshi Morimoto $^{10}$

${ }^{1}$ Department of Clinical Epidemiology, Hyogo College of Medicine, Nishinomiya, Hyogo, Japan

2 Department of Infectious Diseases, Shimane Prefectural Central Hospital, Izumo, Shimane, Japan

${ }^{3}$ Department of Pharmacy, Shimane Prefectural Central Hospital, Izumo, Shimane, Japan

${ }^{4}$ Shimane Prefectural Central Hospital, Izumo, Shimane, Japan

${ }^{5}$ Center for Health Surveillance \& Preventive Medicine, Tokyo Medical University, Tokyo, Japan

6 Education and Training Center for Students and Professionals in Healthcare, Hyogo College of Medicine, Nishinomiya, Hyogo, Japan

Appl Clin Inform 2020;11:846-856.
Address for correspondence Takeshi Morimoto, MD, PhD, MPH, Department of Clinical Epidemiology, Hyogo College of Medicine, Nishinomiya, Hyogo 663-8501, Japan (e-mail: morimoto@kuhp.kyoto-u.ac.jp).

\section{Abstract}

Keywords

- clinical decision support system

- adverse drug event

- renal dysfunction

- hepatic dysfunction

- renal dose adjustment
Background Medication dose adjustment is crucial for patients with renal dysfunction (RD). The assessment of renal function is generally mandatory; however, the renal function may change during the hospital stay and the manual assessment is sometimes challenging.

Objective We developed the clinical decision support system (CDSS) that provided a recommended dose based on automated calculated renal function.

Methods We conducted a prospective cohort study in a single teaching hospital in Japan. All hospitalized patients were included except for obstetrics/gynecology and pediatric wards between September 2013 and February 2015. The CDSS was implemented on December 2013. Renal and hepatic dysfunction (HD) were defined as changes in the estimated glomerular filtration rate (eGFR) and alanine aminotransferase or alkaline phosphatase levels based on these measurements during hospital stay. These measurements were obtained before (phase I), after (phase II), and 1 year after (phase III) the CDSS implementation.

Results We included 6,767 patients (phase I: 2,205; phase II: 2,279; phase III: 2,283). The patients' characteristics were similar among phases. Changes in eGFR were similar among phases, but the incidence of RD increased in phase III (phase I: 228 [10.3\%]; phase II: 260 [11.4\%]; phase III: 296 [13.0\%], $p=0.02$ ). However, the differences in received

July 8,2020

accepted after revision

October 7, 2020
DOI https://doi.org/

$10.1055 / \mathrm{s}-0040-1721056$. ISSN 1869-0327. (c) 2020. The Author(s).

This is an open access article published by Thieme under the terms of the Creative Commons Attribution-NonDerivative-NonCommercial-License, permitting copying and reproduction so long as the original work is given appropriate credit. Contents may not be used for commercial purposes, or adapted, remixed, transformed or built upon. (https://creativecommons.org/ licenses/by-nc-nd/4.0/) Georg Thieme Verlag KG, Rüdigerstraße 14, 70469 Stuttgart, Germany 
incidences of RD were not statistically significant after adjusting for eGFR at baseline and age. The incidences of HD were also similar among phases (phase I: 175 [13.2\%]; phase II: 171 [12.9\%]; phase III: 167 [12.2\%], $p=0.72$ ).

Conclusion The CDSS implementation did not affect the incidence of renal and HD and changes in renal and hepatic function among hospitalized patients. The effectiveness of the CDSS with renal-guided doses should be investigated with respect to other endpoints.

\section{Background and Significance}

Renal dysfunction (RD) and hepatic dysfunction (HD) are common adverse drug events (ADEs) due to medication use among hospitalized patients. ${ }^{1,2}$ Drug-induced RD accounts for approximately $1 \%$ of all hospitalizations. ${ }^{3}$ Patients with preexisting RD are at a much higher risk of developing ADEs as renal excretion of drugs leads to elevated blood concentration. ${ }^{4}$ Approximately $12 \%$ of adult inpatients in a teaching hospital were reported to have RD during their hospital stay. ${ }^{5}$ In addition, a high incidence of ADEs has been associated with old age, ${ }^{6}$ which is considered a risk factor for ADEs. Therefore, appropriate prescription in consideration of the patient's renal function is crucial in the future super-aging society. ${ }^{7}$

Similarly, the liver is also an organ that metabolizes and excretes drugs. Although primarily evoked by the hepatic excretion of drugs, HDs may occur as a result of elevated drug concentration caused by RD. ${ }^{8}$ The RD and HD seem to have different adverse events due to medication use, but both are the most common toxicities, and have an increased incidence with regard to age, and are related to each other. ${ }^{9}$ Thus, appropriate renal excretion of drugs may improve the incidence of HD due to medication use as well as RD.

The appropriate doses of renally excreted drugs are sometimes difficult to determine because some elderly patients with normal creatinine $(\mathrm{Cr})$ levels may have RD. Therefore, physicians should prescribe these drugs based on the calculated renal function, such as $\mathrm{Cr}$ clearance or estimated glomerular filtration rate (eGFR). ${ }^{10,11}$ However, such calculations are bothersome, and it remains difficult to distinguish between drugs requiring renal adjustment and drugs not requiring such adjustment in daily clinical practice. This could be resolved by a clinical decision support system (CDSS) available in developed countries. ${ }^{12-14}$ The CDSS is equipped with a list of recommended and appropriate drug doses that could be adjusted for patients with RD at each drug ordering step. ${ }^{15,16}$ We have developed our own CDSS, which promotes appropriate prescriptions for patients with RD. ${ }^{17}$

\section{Objectives}

Implementation of CDSS has improved the appropriate prescription rates, but its effectiveness on patient outcomes, such as occurrence of ADEs, is not well studied. ${ }^{18-22}$ Therefore, we conducted this prospective cohort study at a tertiary care teaching hospital to investigate the effectiveness of CDSS with renal adjustment capability on subsequent changes in renal and hepatic functions of hospitalized patients. We hypothesized that the CDSS with renal adjustment would prevent the deterioration of renal or hepatic function, which were common toxicities of medication use.

\section{Methods}

\section{Study Design and Patient Population}

The Japan Adverse Drug Event (JADE) study was a series of cohort studies that evaluated the epidemiology of ADEs and medication errors in the real-world settings. ${ }^{6,23-25}$ Using the JADE study series, we analyzed data from a prospective cohort study conducted from September 2013 to February 2015 at a tertiary care teaching hospital where the CDSS with renal adjustment was implemented during the study period. The hospital had a total of 634 beds with 13 medical and 11 surgical divisions and an intensive care unit. We included all patients with and without RD to show the impact of CDSS on the hospital as whole. The obstetrics/gynecology and pediatric wards were excluded because they had a low prevalence of patients with RD and low rates of medication use. We collected data for a 3-month period for each phase: phase I was from September to November 2013 before the CDSS implementation; phase II was from December 2013 to February 2014 just after the CDSS implementation on December 1, 2013; and phase III was from December 2014 to February 2015. The 3-month study period was set because the mean length hospital stay was 14 days in Japan and 3 months were considered long enough to include 3,000 patients and follow-up with most of them at each phase.

Patients aged $\geq 15$ years admitted to the hospital for three study periods were included (-Figure 1 ). We excluded patients with an eGFR value of $15 \mathrm{~mL} / \mathrm{min} / 1.73 \mathrm{~m}^{2}$ or lower on admission and those without eGFR values on admission or during the follow-up period.

The study was approved by the institutional review board of the hospital (approval number: Chu-Rin R 12055), and the board waived the requirement of written informed consent because all data were obtained as part of daily routine practice and the opt-out method was used as the consent.

\section{Clinical Decision Support System Implementation}

The master list of drugs necessitating renal adjustment was developed based on the package inserts, the practice guideline for chronic kidney disease (CKD) published in 2012, ${ }^{26}$ and the guidelines for antimicrobial use. ${ }^{27}$ We then implemented the drug master list in the computerized ordering 


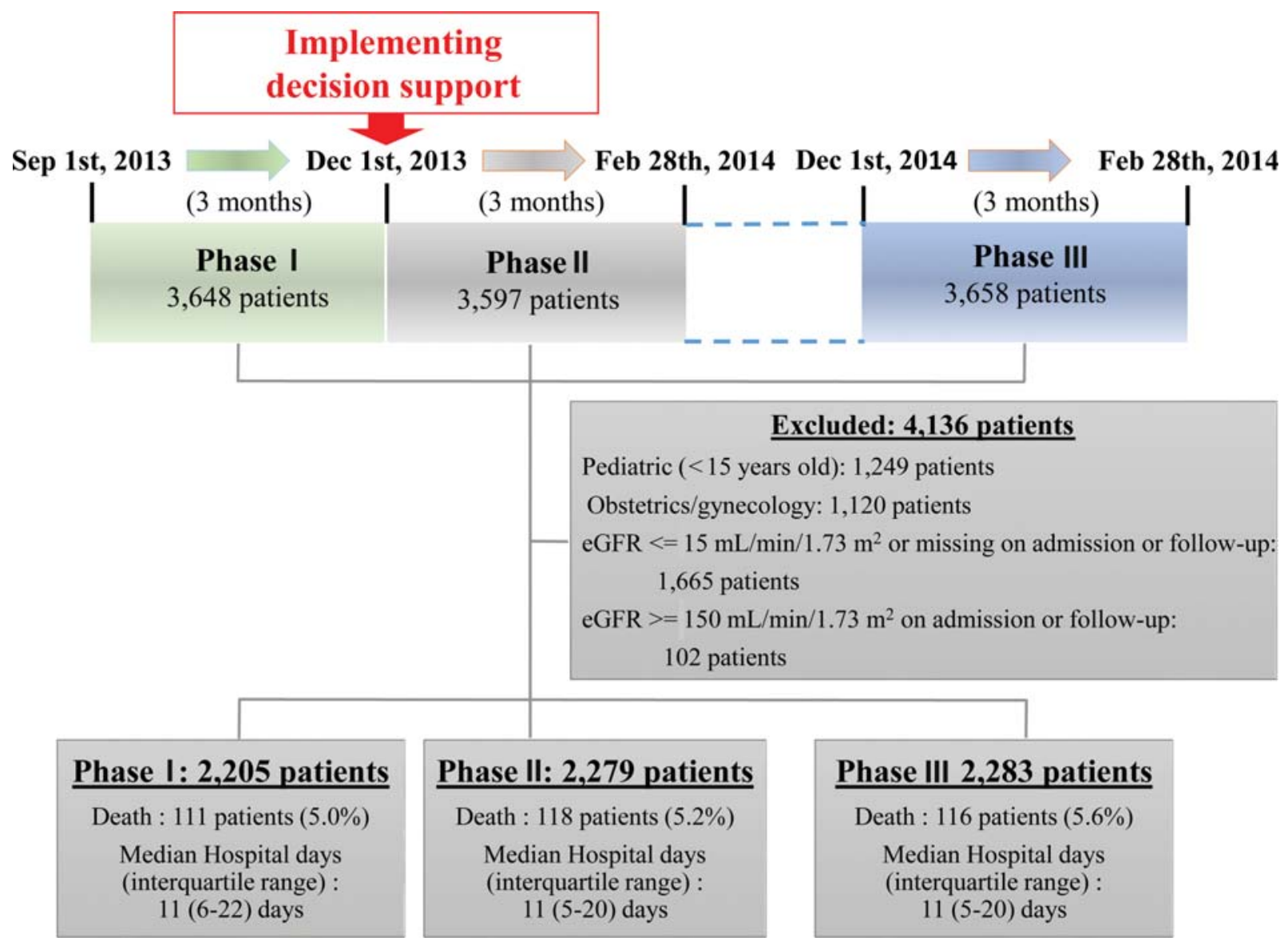

Fig. 1 Study flow chart.

system on the electronic medical record and constructed the CDSS (Supplemental Table [available in the online version]). When physicians prescribed any drug on the master list, the prescription guide with the recommended dose for calculated $\mathrm{Cr}$ clearance was displayed at the time of drug selection. This function was available for all patients including those without RD or HD because physicians might select different doses under the special conditions. Physicians could not only select one order with the appropriate dose from the list of recommended doses but also overwrite it and select other doses due to clinical reasons, such as offlabel use. The drugs were continued until the physician in charge decided to stop or discharge the patients. The CDSS was active from phase I to III and displayed the prescription guide during phase II to phase III. The CDSS did not display the prescription and it worked in the background, keeping the log during phase I.

\section{Data Collection}

All data pertaining to patients' characteristics, laboratory tests, and drug prescriptions were automatically stored in the electronic medical record. The actions of the CDSS were also recorded. The variables collected were patient's age, admission date, ordering physician, admitting diagnosis, height, weight, eGFR, $\mathrm{Cr}$ clearance level, serum $\mathrm{Cr}$ level, and hepatic function values such as alanine aminotransferase (ALT) and alkaline phosphatase (ALP) levels. In addition, the eGFR values in this study were calculated using the formula recommended by the Japanese Nephrology Society as showed below ${ }^{28}$ :

$$
\begin{aligned}
& \mathrm{eGFR}\left(\mathrm{mL} / \mathrm{min} / 1.73 \mathrm{~m}^{2}\right)=194 \times \text { serum } \mathrm{Cr}^{-1.094} \\
& \times \operatorname{Age}^{-0.287} \times 0.739(\text { in females })
\end{aligned}
$$

In terms of medication use, the name, dose and frequency of the prescribed drug, and actions of ordering physicians against the prescription guides were recorded.

\section{Outcomes}

The outcomes were RD and HD (-Table 1). The RD was diagnosed based on the practice guideline for CKD published in $2012,{ }^{26}$ including renal impairment (RI), decrease in eGFR, and change in eGFR ( $\left.\mathrm{mL} / \mathrm{min} / 1.73 \mathrm{~m}^{2}\right)$, while HD was diagnosed based on a manual for the diagnostic criteria for druginduced liver injury, ${ }^{29}$ and American Gastroenterology Society guidelines, ${ }^{30}$ including HD in ALT (HD-ALT) and HD in ALP (HD-ALP).

\section{Statistical Analyses}

The incidences of RD and HD and the changes in measurements were compared among phases as a whole and stratified by the eGFR value ( $\geq 60$ vs. $<60 \mathrm{~mL} / \mathrm{min} / 1.73 \mathrm{~m}^{2}$ ) and age ( $<65$ vs. $\geq 65$ years) on admission. Because the baseline values of eGFR could be associated with the following changes in eGFR, we adjusted for eGFR as well as age at 
Table 1 Definition of renal and hepatic dysfunction

\begin{tabular}{|c|c|c|c|}
\hline \multicolumn{2}{|l|}{ Outcomes } & \multicolumn{2}{|l|}{ Definitions } \\
\hline \multicolumn{4}{|c|}{ Renal dysfunction } \\
\hline \multirow{5}{*}{\multicolumn{2}{|c|}{ Renal impairment }} & Baseline eGFR $\left(\mathrm{mL} / \mathrm{min} / 1.73 \mathrm{~m}^{2}\right)$ & Minimum eGFR during the follow-up period $\left(\mathrm{mL} / \mathrm{min} / 1.73 \mathrm{~m}^{2}\right)$ \\
\hline & & $\geq 60$ & $<60$ \\
\hline & & $45-59$ & $<45$ \\
\hline & & $30-44$ & $<30$ \\
\hline & & $<30$ & $<15$ \\
\hline \multicolumn{2}{|c|}{ Decrease in eGFR } & \multicolumn{2}{|c|}{$\begin{array}{l}\text { Baseline eGFR } \\
\text { Minimum eGFR during the follow-up period } \geq 15 \mathrm{~mL} / \mathrm{min} / 1.73 \mathrm{~m}^{2}\end{array}$} \\
\hline \multicolumn{2}{|c|}{$\begin{array}{l}\text { Changes in eGFR } \\
\left(\mathrm{mL} / \mathrm{min} / 1.73 \mathrm{~m}^{2}\right)\end{array}$} & \multicolumn{2}{|c|}{$\begin{array}{l}\text { Baseline eGFR } \\
\text { Minimum eGFR during the follow-up period }\end{array}$} \\
\hline \multicolumn{4}{|c|}{ Hepatic dysfunction } \\
\hline \multirow{9}{*}{$\begin{array}{l}\text { Hepatic } \\
\text { dysfunction } \\
\text { in ALT }\end{array}$} & & Baseline ALT (IU/L) & Maximum ALT during the follow-up period (IU/L) \\
\hline & \multirow[t]{4}{*}{ Male } & $<33$ & $>66$ \\
\hline & & $\geq 33,<165$ & $>165$ \\
\hline & & $\geq 165,<495$ & $>495$ \\
\hline & & $\geq 495$ & $>1,000$ \\
\hline & \multirow[t]{4}{*}{ Female } & $<25$ & $>50$ \\
\hline & & $\geq 25,<125$ & $>125$ \\
\hline & & $\geq 125,<375$ & $>375$ \\
\hline & & $\geq 375$ & $>1,000$ \\
\hline \multirow{5}{*}{\multicolumn{2}{|c|}{$\begin{array}{l}\text { Hepatic } \\
\text { dysfunction } \\
\text { in ALP }\end{array}$}} & Baseline ALP (IU/L) & Maximum ALP during the follow-up period (IU/L) \\
\hline & & $<325$ & $>650$ \\
\hline & & $\geq 325,<1,625$ & $>1,625$ \\
\hline & & $\geq 1,625,<4,875$ & $>4,875$ \\
\hline & & $\geq 4,875$ & $>10,000$ \\
\hline
\end{tabular}

Abbreviations: ALP, alkaline phosphatase; ALT, alanine transaminase; eGFR, estimated glomerular filtration rate.

baseline in the logistic regression models for RD and HD, and linear regression models for changes in measurements with dummy variables for each phase was used to estimate the adjusted $p$-values.

Continuous variables are presented as mean \pm standard deviation or median (interquartile range) and compared with the analysis of variance. Categorical variables are shown as numbers and percentages and compared using the Chi-square test. All reported $p$-values were two-tailed, and $p$-values less than 0.01 were considered statistically significant considering the many outcomes. JMP 14.2 (SAS Institute Inc., Cary, North Carolina, United States) was used for all statistical analyses.

\section{Results}

During the study periods, there were 10,903 inpatients (phase I, 3,648; phase II, 3,597; phase III, 3,658) admitted to the hospital. We included 6,767 patients (phase I, 2,205; phase II, 2,279; and phase III, 2,283) who met the inclusion criteria (-Figure 1). Among them, 3,044 (45\%) were males, and the mean age was 69 (standard deviation $=17$ ) years.
The patients' characteristics were similar between phases, and those with $\mathrm{RD}\left(<60 \mathrm{~mL} / \mathrm{min} / 1.73 \mathrm{~m}^{2}\right)$ were one-third of all admitted patients (-Table 2 ). The median (interquartile range) length of hospital stay was 11 (6-21) days.

The appropriate rates of prescribed drugs which necessitate the adjustment for renal function were improved from $90.7 \%$ $(4,174 / 4,602)$ during phase I to $95.8 \%(4,789 / 4,999)$ phase II among all admitted patients; they were $78.5 \%(1,429 / 1,820)$ and $89.5 \%(1,729 / 1,931)$ of patients with $\mathrm{Cr}$ clearance less than $50 \mathrm{~mL} / \mathrm{min}$ during phase I to phase II, respectively. ${ }^{17}$

\section{Effect of Clinical Decision Support System Implementation on Renal and Hepatic Function}

The incidence rates of RI and the changes in eGFR were similar among phases, but the decrease in eGFR $\geq 15 \mathrm{~mL} / \mathrm{min} / 1.73 \mathrm{~m}^{2}$ increased in phase III (phase I, 228 [10.3\%]; phase II, 260 [11.4\%]; phase III, 296 [13.0\%]; $p=0.02$ ), compared with that in phase I. However, after adjusting for eGFR and age at baseline, the incidences of RD were not statistically significant ( - Table 2).

On the contrary, the incidences of HD were similar among phases (phase I, 175 [13.2\%]; phase II, 171 [12.9\%]; phase III, 
Table 2 Patient characteristics on admission

\begin{tabular}{|c|c|c|c|}
\hline & Phase I & Phase II & Phase III \\
\hline & (2,205 patients) & (2,279 patients) & (2,283 patients) \\
\hline Age $(y)^{a}$ & $68.9 \pm 17.1$ & $69.3 \pm 16.8$ & $70.3 \pm 16.9$ \\
\hline$<65(n \%)$ & 748 (33.9) & $751(33.0)$ & $677(29.7)$ \\
\hline$\geq 65(n \%)$ & $1,457(66.1)$ & $1,528(67.0)$ & $1,606(70.3)$ \\
\hline Male $(n \%)^{c}$ & $1,195(54.2)$ & $1,250(54.9)$ & $1,278(56.0)$ \\
\hline Height $(\mathrm{cm})^{\mathrm{a}}$ & $157.8 \pm 10.1$ & $158.0 \pm 9.6$ & $158.0 \pm 10.0$ \\
\hline Weight $(\mathrm{kg})^{\mathrm{a}}$ & $54.5 \pm 12.2$ & $55.4 \pm 12.2$ & $54.9 \pm 12.2$ \\
\hline $\operatorname{BMI}\left(\mathrm{kg} / \mathrm{m}^{2}\right)^{\mathrm{a}}$ & $21.9 \pm 3.8$ & $22.2 \pm 3.9$ & $22.0 \pm 3.7$ \\
\hline eGFR $\left(\mathrm{mL} / \mathrm{min} / 1.73 \mathrm{~m}^{2}\right)^{\mathrm{a}}$ & $69.4 \pm 24.3$ & $72.0 \pm 25.9$ & $72.5 \pm 25.9$ \\
\hline$\geq 60(n \%)$ & $1,464(66.4)$ & $1,552(68.1)$ & $1,573(68.9)$ \\
\hline$<60(n \%)$ & $741(33.6)$ & 727 (31.9) & $710(31.1)$ \\
\hline $\mathrm{Cr}(\mathrm{mg} / \mathrm{dL})^{\mathrm{b}}$ & $0.77(0.63-0.96)$ & $0.75(0.6-0.94)$ & $0.74(0.6-0.95)$ \\
\hline BUN (mg/dL) ${ }^{b}$ & $15.2(11.7-20.7)$ & $15.6(12.1-21.2)$ & $15.6(12-21.3)$ \\
\hline AST $(I U / L)^{b}$ & $23(17-32)$ & $23(18-34)$ & $24(18-35)$ \\
\hline $\operatorname{ALT}(\mathrm{IU} / \mathrm{L})^{\mathrm{b}}$ & $17(12-27)$ & $18(12-29)$ & $18(12-28)$ \\
\hline $\operatorname{ALP}(\mathrm{IU} / \mathrm{mL})^{\mathrm{b}}$ & $246(191-321)$ & $248(193-323)$ & $255(198-343)$ \\
\hline T-Bil $(\mathrm{mg} / \mathrm{dL})^{\mathrm{b}}$ & $0.7(0.5-1.0)$ & $0.7(0.5-1.0)$ & $0.7(0.5-1.0)$ \\
\hline \multicolumn{4}{|l|}{ Primary diseases for admission (ICD-10 classification; $n \%)^{c}$} \\
\hline Neoplasms & $598(27.1)$ & $585(25.7)$ & $661(29.0)$ \\
\hline Diseases of the circulatory system & $420(19.0)$ & $495(21.7)$ & $414(18.1)$ \\
\hline Diseases of the digestive system & $335(15.2)$ & $327(14.3)$ & $300(13.2)$ \\
\hline Injury and poisoning & $260(11.8)$ & $248(10.9)$ & $242(10.6)$ \\
\hline Diseases of the respiratory system & $167(7.6)$ & $185(8.1)$ & $210(9.2)$ \\
\hline Diseases of the genitourinary system & $67(3.0)$ & $66(2.9)$ & $64(2.8)$ \\
\hline Endocrine, nutritional, and metabolic diseases & $61(2.8)$ & $59(2.6)$ & $68(3.0)$ \\
\hline Mental and behavioral disorders & $59(2.7)$ & $41(1.8)$ & $59(2.6)$ \\
\hline $\begin{array}{l}\text { Symptoms, signs, abnormal clinical findings, } \\
\text { and abnormal laboratory findings not otherwise classified }\end{array}$ & $53(2.4)$ & $65(2.9)$ & $69(3.0)$ \\
\hline Certain infectious diseases & $51(2.3)$ & $55(2.4)$ & $62(2.7)$ \\
\hline Diseases of the nervous system & $39(1.8)$ & $69(3.0)$ & $39(1.7)$ \\
\hline
\end{tabular}

Abbreviations: ALP, alkaline phosphatase; ALT, alanine transaminase; AST, aspartate transaminase; BMI, body mass index; BUN, blood urea nitrogen; $\mathrm{Cr}$, creatinine; eGFR, estimated glomerular filtration rate; ICD-10, International Classification of Diseases-10.

${ }^{\mathrm{a}}$ Mean \pm standard deviation.

bMedian (25\% quartile and $75 \%$ quartile).

167 [12.2\%]; $p=0.72$ ), and they were similar after adjusting for eGFR and age at baseline.

\section{Effect on Renal and Hepatic Function Stratified by Baseline Estimated Glomerular Filtration Rate}

Among patients with eGFR $\geq 60 \mathrm{~mL} / \mathrm{min} / 1.73 \mathrm{~m}^{2}$ on admission, decrease in eGFR $\geq 15 \mathrm{~mL} / \mathrm{min} / 1.73 \mathrm{~m}^{2}$ and change in eGFR in phase III significantly increased compared with those in phase I ( - Table 3). In the case of eGFR $<60 \mathrm{~mL} / \mathrm{min} / 1.73 \mathrm{~m}^{2}$ on admission, there was no significant difference in the decrease in eGFR $\geq 15 \mathrm{~mL} / \mathrm{min} / 1.73 \mathrm{~m}^{2}$ and change in eGFR among phases.
There was no significant difference in the incidence of HD among phases between patients with eGFR $\geq 60$ and those with $<60$.

\section{Effect on the Renal and Hepatic Function Stratified by Age} Between patients aged $<65$ and those $\geq 65$ years, there was no significant difference in the decrease in eGFR $\geq 15 \mathrm{~mL} /$ $\mathrm{min} / 1.73 \mathrm{~m}^{2}$ and change in eGFR among phases (-Table 4).

Additionally, there was no significant difference in the incidence of HD among phases between patients aged $<65$ and $\geq 65$ years ( - Table 5 ). 


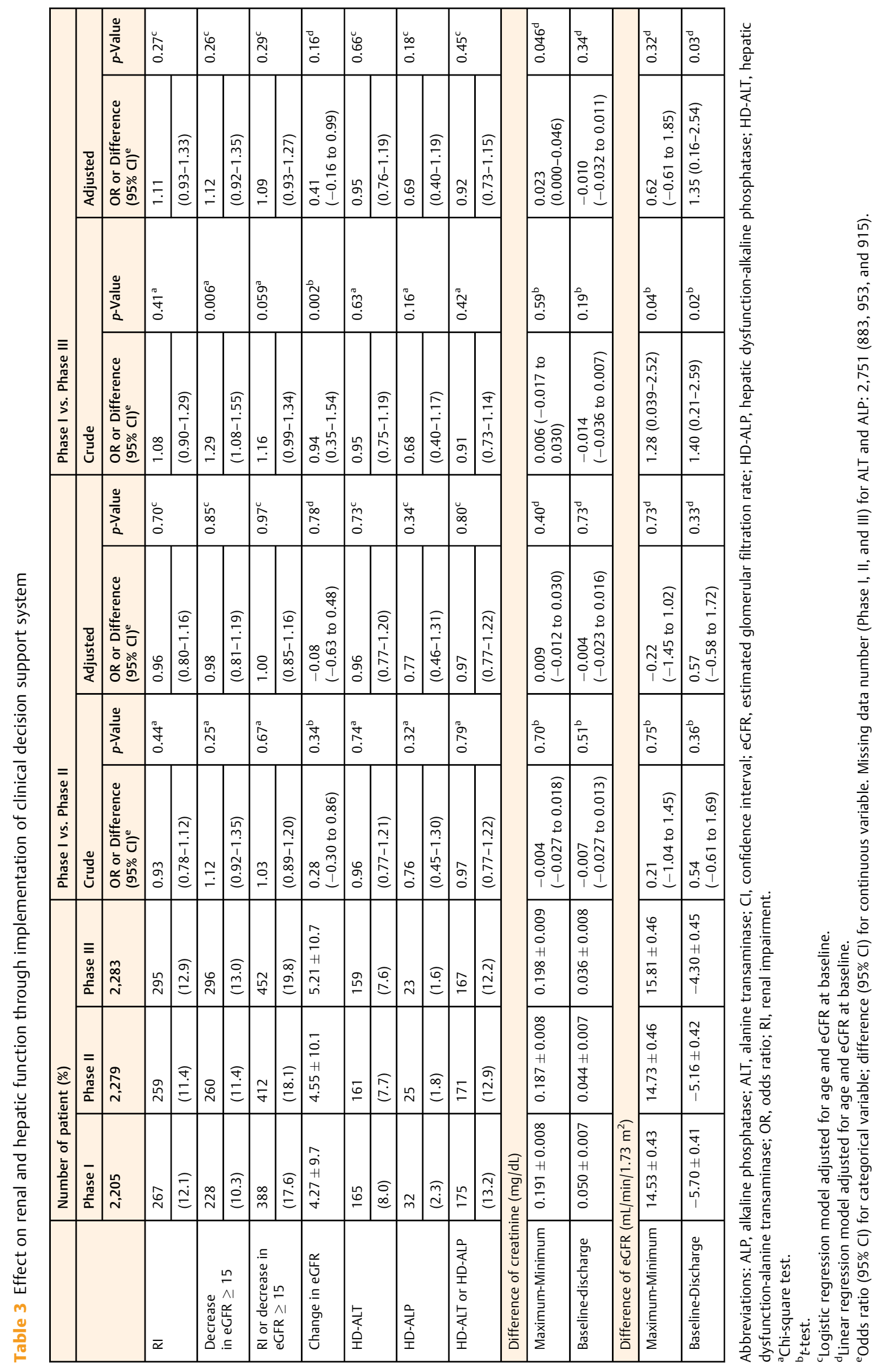




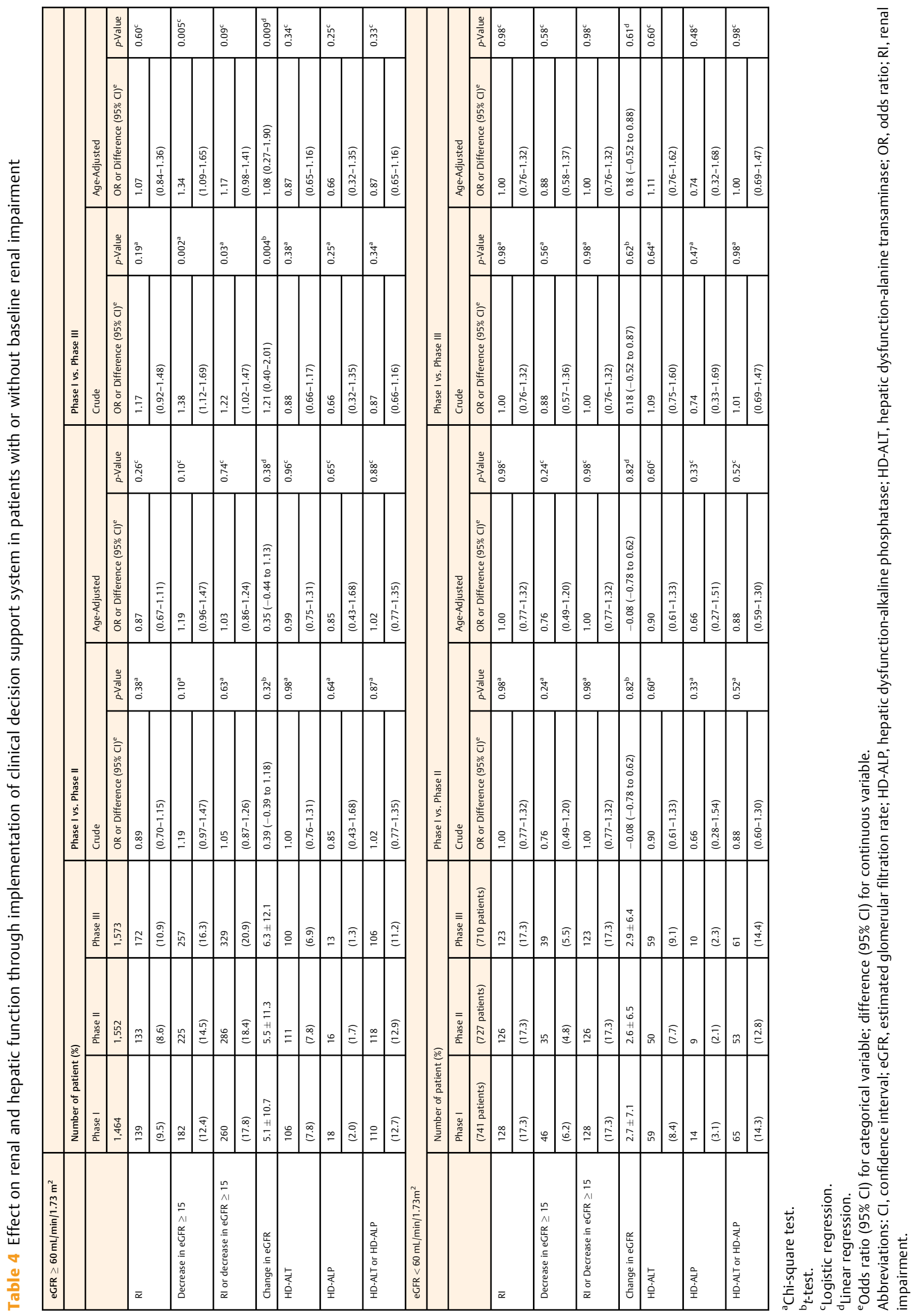




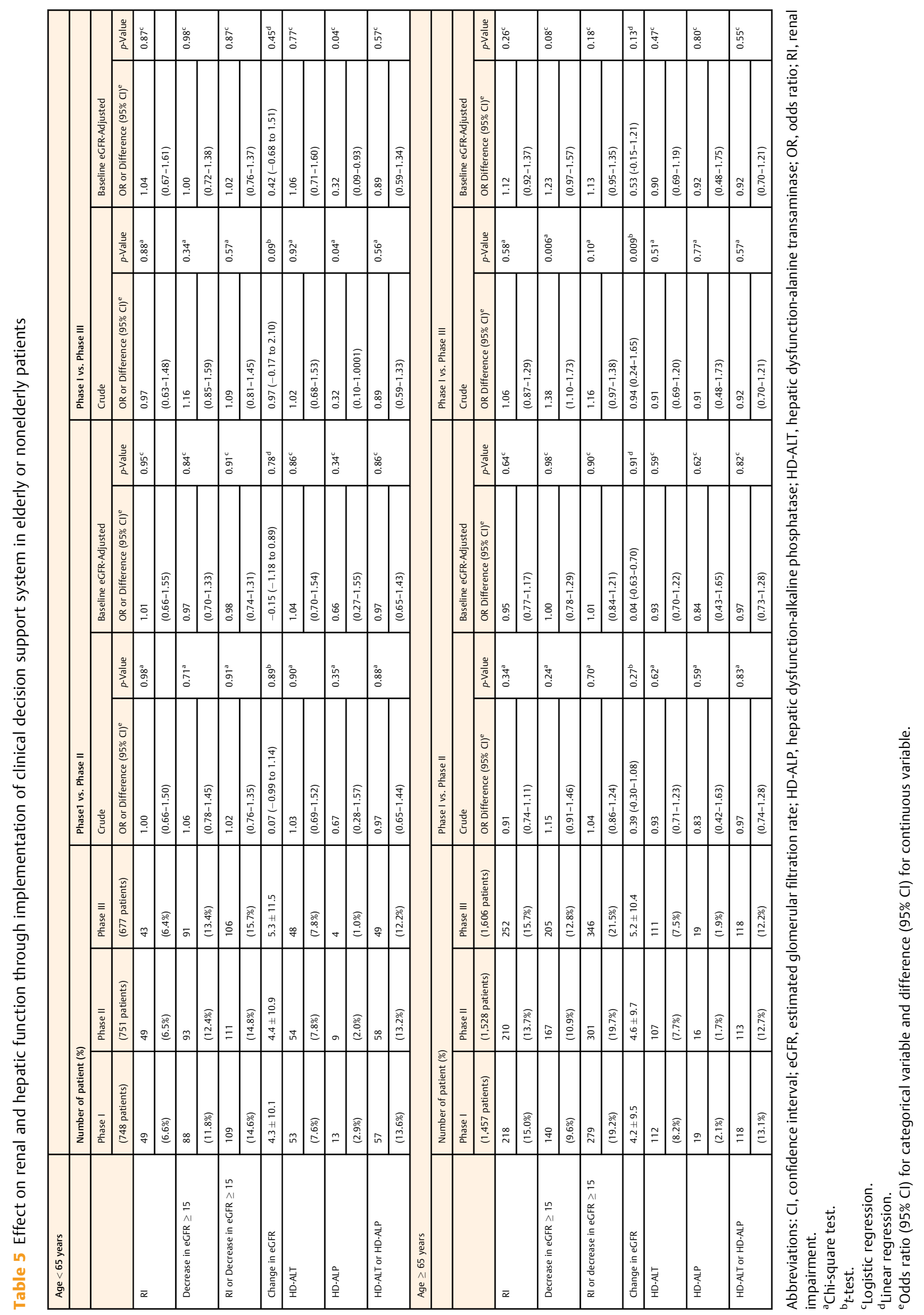




\section{Discussion}

We investigated the effectiveness of the CDSS implementation on renal and hepatic function of inpatients. The amount of eGFR change during the study period and the proportion of patients with eGFR changes $\geq 15 \mathrm{~mL} / \mathrm{min} / 1.73 \mathrm{~m}^{2}$ were significantly greater 1 year after the implementation of the system (phase III) than before the implementation (phase I). However, this difference was not observed when the baseline age and eGFR were adjusted. In contrast, in the stratified group without RI (eGFR $\geq 60 \mathrm{~mL} / \mathrm{min} / 1.73 \mathrm{~m}^{2}$ ), the amount of eGFR changes during the study period and the proportion of patients with eGFR changes $\geq 15 \mathrm{~mL} / \mathrm{min} / 1.73 \mathrm{~m}^{2}$ were significantly larger 1 year after the system implementation than before the implementation. However, there was no significant difference between phases in the stratified groups with RI (eGFR $<60 \mathrm{~mL} / \mathrm{min} / 1.73 \mathrm{~m}^{2}$ ) and the stratified groups of elderly (age $\geq 65$ years) and nonelderly (age $<65$ years) patients. Thus, the CDSS implementation with renal adjustment did not prevent the deterioration of renal and hepatic function during hospital stay.

Our findings suggested that the improved prescription did not improve renal and hepatic outcomes. The discrepancy between the improved prescription rate and unchanged RD or HD during the hospital stay should be carefully interpreted. Medications that necessitate the dose adjustment based on renal function were limited in the hospital. In addition, the follow-up period in the study (median hospital days, 11) was short because renal function is generally observed in the longer term. Therefore, this function may be improved when these measurements are followed up after discharge.

Several studies investigated the effectiveness of the CDSS with the prescription guide for renal adjustment. ${ }^{18-22}$ Most of these studies reported the process, including the appropriateness of prescription, but not the patient outcomes, such as renal function. In addition, there were no reports on the relationship between the CDSS with renal adjustment and subsequent HD. However, we also could not demonstrate the effectiveness of the CDSS in the prevention of ADEs.

The appropriate prescription rate certainly improved with the CDSS implementation, which alerts the physicians' prescriptions in our study. As the study center was a tertiary care hospital, many physicians in charge were senior physicians. The effectiveness of the CDSS may be elucidated if there were more physicians in training. Therefore, the effectiveness of the CDSS on clinical outcomes should be evaluated in other settings such as a teaching hospital or primary care.

Our study has several limitations. First, this study was a before and after design; thus, the backgrounds of the patients were unnecessarily similar among phases although we adjusted for age and the baseline renal function. We should consider many other factors, such as patients' conditions that could contribute to a decline in renal and hepatic functions during hospitalization to establish the effectiveness of CDSS on RD and HD. However, we included all admitted patients in a general hospital, and the patient conditions were too diverse to be adjusted. Therefore, other studies among patients with simple or uniform diseases could be conducted to reinforce our findings. Second, we set several outcomes based on the eGFR, ALT, and ALP values because the magnitude of changes over a 3-month period was too small to evaluate the clinically meaningful dysfunctions. For instance, one of the definitions of CKD was the measurements of eGFR on at least two occasions, 90 days apart (with or without the markers of kidney damage). ${ }^{31}$ Therefore, further studies need to evaluate the effectiveness of the CDSS with renal adjustment on renal and hepatic functions for inpatients after the discharge or those in for longer term. ${ }^{32}$ Third, we observed RD and HD incidences of the overall cohorts, and two-third of the included patients did not have RD on admission and were not the target population of the CDSS. Therefore, if we analyzed only patients with actual guide for existing RD, the effectiveness of CDSS should be more prominent. However, we conducted this research on all patients to measure the overall impact of CDSS on hospital administration. Fourth, medications registered in the master list of this study were limited. The master list of drugs necessitating renal adjustment had initially been developed; however, it was not updated during the study period. If a new drug requiring dose adjustment for renal function was prescribed during the study period, the physician may not have been alerted and would not have been aware of the inappropriate prescription. In clinical practice, it is necessary to update the medication lists with adjustment for renal function. Fifth, the study setting was a general hospital and the background characteristics of admitted patients were too diverse. Therefore, we could not evaluate the effectiveness of CDSS on patients with specific characteristics. Finally, we conducted this study at a single center, and the generalizability was limited. If we could implement the CDSS at multiple centers, the generalizability of this study could be established.

\section{Conclusion}

The CDSS with renal adjustment did not improve the RD and HD during hospital stay. The effectiveness of the CDSS with renal adjustment on RD and HD for a short term remains undetermined and should be evaluated in long-term studies and from other perspectives.

\section{Clinical Relevance Statement}

Many CDSS are equipped with medication dose adjustment based on renal function, but their effectiveness was assessed by process measures such as appropriate prescription rates.

The prospective cohort study at inpatient setting showed implementation of CDSS with medication dose adjustment based on renal function did not decrease the incidences of renal and HD during the hospitalization.

The effectiveness of the CDSS with medication dose adjustment based on renal function should be investigated with respect to other endpoints and longer perspectives. 


\section{Multiple Choice Questions}

1. When physicians prescribed any drug necessitate the dose adjustment, what measurement of patient was used to calculate the appropriate dose with the CDSS?
a. $\mathrm{Cr}$ clearance
b. eGFR
c. BMI
d. Body surface area

Correct Answer: The correct answer is option a. The master list of drugs necessitating renal adjustment was developed based on the package inserts, and many package inserts set appropriate doses by $\mathrm{Cr}$ clearance in Japan.

2. Which of the following was the targeted patients to be analyzed in the study?
a. Patients with RD
b. Patients with HD
c. Patients with RD and without RD
d. Patients with RD and without HD

Correct Answer: The correct answer is option c. We included all patients with RD and without RD because we should show the impact of CDSS on the hospital as whole.

\section{Protection of Human and Animal Subjects}

This study was approved by the institutional review board at the hospital.

\section{Funding}

This work was supported by JSPS KAKENHI (grant numbers: JP17689022, JP21659130, JP22390103, JP23659256, JP26293159, and JP18H03032); Ministry of Health, Labor and Welfare of Japan (grant numbers: H26-Iryo-012 and H28-ICT-004); Pfizer Health Research Foundation; and the Uehara Memorial Foundation.

\section{Conflict of Interest}

R.W. is an employee of Novartis Pharma KK. All other authors do not have any conflict of interest.

\section{Acknowledgments}

This study used part of the data from JADE Study with CDSS. We are indebted to Dr. Kiyoshi Kikuchi, Mr. Eisaku Hirano, Mr. Kazuo Takeshita, Mr. Shuichi Kurahashi for their development of CDSS, and Mr. Koichiro Ichiki and Mr. Akito Uchio for their data management.

\section{References}

1 Morimoto T, Gandhi TK, Seger AC, Hsieh TC, Bates DW. Adverse drug events and medication errors: detection and classification methods. Qual Saf Health Care 2004;13(04):306-314

2 Takahashi Y, Sakuma M, Murayama H, Morimoto T. Effect of baseline renal and hepatic function on the incidence of adverse drug events: the Japan Adverse Drug Events study. Drug Metab Pers Ther 2018;33(04):165-173
3 Usui J, Yamagata K, Imai E, et al. Clinical practice guideline for drug-induced kidney injury in Japan 2016: digest version. Clin Exp Nephrol 2016;20(06):827-831

4 Alkhunaizi AM, Schrier RW. Management of acute renal failure: new perspectives. Am J Kidney Dis 1996;28(03):315-328

5 Fujii T, Uchino S, Takinami M, Bellomo R. Subacute kidney injury in hospitalized patients. Clin J Am Soc Nephrol 2014;9(03):457-461

6 Morimoto T, Sakuma M, Matsui K, et al. Incidence of adverse drug events and medication errors in Japan: the JADE study. J Gen Intern Med 2011;26(02):148-153

7 Rowe JW, Andres R, Tobin JD, Norris AH, Shock NW. The effect of age on creatinine clearance in men: a cross-sectional and longitudinal study. J Gerontol 1976;31(02):155-163

8 Verbeeck RK. Pharmacokinetics and dosage adjustment in patients with hepatic dysfunction. Eur J Clin Pharmacol 2008; 64(12):1147-1161

9 Pichette V, Leblond FA. Drug metabolism in chronic renal failure. Curr Drug Metab 2003;4(02):91-103

10 Verbeeck RK, Musuamba FT. Pharmacokinetics and dosage adjustment in patients with renal dysfunction. Eur J Clin Pharmacol 2009;65(08):757-773

11 Spruill WJ, Wade WE, Cobb HH III. Comparison of estimated glomerular filtration rate with estimated creatinine clearance in the dosing of drugs requiring adjustments in elderly patients with declining renal function. Am J Geriatr Pharmacother 2008;6 (03):153-160

12 Ibáñez-Garcia S, Rodriguez-Gonzalez C, Escudero-Vilaplana V, et al. Development and evaluation of a clinical decision support system to improve medication safety. Appl Clin Inform 2019;10 (03):513-520

13 Kirkendall ES, Spires WL, Mottes TA, Schaffzin JK, Barclay C, Goldstein SL. Development and performance of electronic acute kidney injury triggers to identify pediatric patients at risk for nephrotoxic medication-associated harm. Appl Clin Inform 2014; 5(02):313-333

14 Wong A, Wright A, Seger DL, Amato MG, Fiskio JM, Bates D. Comparison of overridden medication-related clinical decision support in the intensive care unit between a commercial system and a legacy system. Appl Clin Inform 2017;8(03):866-879

15 Chertow GM, Lee J, Kuperman GJ, et al. Guided medication dosing for inpatients with renal insufficiency. JAMA 2001;286(22): 2839-2844

16 Awdishu L, Coates CR, Lyddane A, et al. The impact of real-time alerting on appropriate prescribing in kidney disease: a cluster randomized controlled trial. J Am Med Inform Assoc 2016;23(03): 609-616

17 Sonoyama T, Niiyama T, Ajiki K, et al. Appropriate drug dosing based on renal function using a decision support system of prescription order entry - display of the proper dosage and dose check -. J Jpn Soc Hosp Pharm 2016;52(08):1013-1017

18 Tawadrous D, Shariff SZ, Haynes RB, Iansavichus AV, Jain AK, Garg AX. Use of clinical decision support systems for kidney-related drug prescribing: a systematic review. Am J Kidney Dis 2011;58 (06):903-914

19 Garg AX, Adhikari NK, McDonald H, et al. Effects of computerized clinical decision support systems on practitioner performance and patient outcomes: a systematic review. JAMA 2005;293(10): 1223-1238

20 Hunt DL, Haynes RB, Hanna SE, Smith K. Effects of computer-based clinical decision support systems on physician performance and patient outcomes: a systematic review. JAMA 1998;280(15): 1339-1346

21 Schedlbauer A, Prasad V, Mulvaney C, et al. What evidence supports the use of computerized alerts and prompts to improve clinicians' prescribing behavior? J Am Med Inform Assoc 2009;16 (04):531-538 
22 Walton R, Dovey S, Harvey E, Freemantle N. Computer support for determining drug dose: systematic review and meta-analysis. BMJ 1999;318(7189):984-990

23 Sakuma M, Ida H, Nakamura T, et al. Adverse drug events and medication errors in Japanese paediatric inpatients: a retrospective cohort study. BMJ Qual Saf 2014;23(10):830-837

24 Ohta Y, Sakuma M, Koike K, Bates DW, Morimoto T. Influence of adverse drug events on morbidity and mortality in intensive care units: the JADE study. Int J Qual Health Care 2014;26(06):573-578

25 Ayani N, Sakuma M, Morimoto T, et al. The epidemiology of adverse drug events and medication errors among psychiatric inpatients in Japan: the JADE study. BMC Psychiatry 2016;16:303

26 Japan nephrology society. [Special issue: Clinical practice guidebook for diagnosis and treatment of chronic kidney disease 2012] Nippon Jinzo Gakkai Shi 2012;54(08):1034-1191

27 Niiyama T, Yokote K, Moriyama F, et al. Approaches to appropriate use of injectable antimicrobial agents and changes in antimicro- bial susceptibility of pseudomon $\alpha$ s aeruginosa. J Jpn Soc Hosp Pharm 2014;50(07):877-881

28 Matsuo S, Imai E, Horio M, et al; Collaborators developing the Japanese equation for estimated GFR. Revised equations for estimated GFR from serum creatinine in Japan. Am J Kidney Dis 2009;53(06):982-992

29 Takikawa H, Onji M, Takamori Y, et al. Proposal of diagnostic criteria of drug induced hepatic injury in DDW-J2004. Kanzo 2005;46(02):85-90

30 Kwo PY, Cohen SM, Lim JK. ACG clinical guideline: evaluation of abnormal liver chemistries. Am J Gastroenterol 2017;112(01):18-35

31 Kidney Disease: Improving Global Outcomes. Chapter 1: Definition and classification of CKD Kidney Int Suppl (2011) 2013;3(01):19-62

32 Vogel EA, Billups SJ, Herner SJ, Delate TPrescriber-Based Clinical Decision Support Systems. Renal Drug Dosing. Effectiveness of Outpatient Pharmacist-Based vs. Appl Clin Inform 2016;7(03):731-744 